\section{Effect of Two Fire Retardants on Postharvest Drying and Flammability of Douglas Fir and Fraser Fir Christmas Trees}

\author{
Gary Chastagner ${ }^{1,3}$ \\ Washington State University, Plant Pathology, Research and Extension \\ Center, 7612 Pioneer Way East, Puyallup, WA 98371
}

\author{
L. Eric Hinesley ${ }^{1}$ \\ Department of Horticultural Science, North Carolina State University, \\ Raleigh, NC 27695
}

\section{Jeff Owen ${ }^{2}$}

Department of Forestry and Environmental Resources, North Carolina State University, Raleigh, NC 27695

Additional index words. Abies fraseri, Pseudotsuga menziesii, fire safety

\begin{abstract}
SafeTree Christmas Tree Fire Retardant was applied to freshly harvested Douglas fir [Pseudotsuga menziesii (Mirb.) Franco] boughs, and RapidCool FRX Christmas Tree Retardant was applied to freshly cut Fraser fir [Abies fraseri (Pursh) Poir.] boughs. The flame retardants were sprayed onto the foliage. Fire retardant accelerated the drying rate of Douglas fir boughs, which increased flammability. RapidCool fire retardant did not slow the drying rate of Fraser fir boughs, and had no effect on moisture content (MC) at ignition, flame time, total burn time, or total foliage consumed. For both species, initial ignition and spread of flame occurred at $60 \%$ to $70 \%$ MC. Fresh boughs did not ignite in burn tests and were not a fire hazard. Twig MC of nontreated Fraser fir increased $20 \%$ during display in water, further decreasing the possibility of ignition when exposed to a flame. Neither product was effective as a fire retardant on boughs of Christmas trees.
\end{abstract}

Concerns about Christmas trees as a potential fire hazard have increased regulations governing where and how trees can be displayed. Although statistics show only $0.1 \%$ of annual household fires in the United States originate in Christmas trees (Koelling, 1998; National Fire Protection Association, 2006a, b), these laws and regulations create difficulties for Christmas tree producers as well as end users of real trees. Local and state

\footnotetext{
Received for publication 26 June 2007. Accepted for publication 9 Aug. 2007.

This research was supported by the Pacific Northwest Christmas Tree Association Advanced Research Fund, the Goodwin Group LLC DBA RapidCool (Lynchburg, VA), and the North Carolina Agricultural Research Service (Raleigh, NC), PPNS no. 0457 Department of Plant Pathology, College of Agricultural, Human, and Natural Resource Sciences Agricultural Research Center project no. 0388, Washington State University, Pullman, WA.

Mention of trade names represents neither an endorsement nor a criticism of similar products not named.

The assistance of Andree DeBauw is gratefully acknowledged.

${ }^{1}$ Professor.

${ }^{2}$ Extension Specialist.

${ }^{3}$ To whom reprint requests should be addressed; e-mail chastag@wsu.edu
}

ordinances and regulations often require flame retardants when real trees are displayed in certain types of buildings (City of Anaheim, n.d.; Gwinnett County Fire Marshal, 2006; Ohio Department of Commerce, 2004; State of California, 2007). Previous research has shown that fire retardants can adversely affect tree quality and safety, and that the most effective way to minimize potential fire hazards associated with dry Christmas trees is to maintain a high moisture content (MC) by displaying them in water, which delays drying (Ahrens and Stephens, 1975; Babrauskas et al., 2001; Chastagner, 1990; Van Wagner, 1963). The objective of this study was to determine the effects of an experimental and a commercially available flame retardant on foliage quality, moisture retention, and flammability of boughs of two important Christmas tree species.

\section{Materials and Methods}

Douglas fir (Pseudotsuga menziesii). On 6 Feb. 2005, the commercially available SafeTree Christmas Tree Fire Retardant (Summit Environmental Corp., Longview, TX) was applied to 4-year-old branches that were harvested the same day from the midcrown area of nonsheared 16-year-old trees of clone 13 growing at Washington State University (WSU),
Puyallup, WA. The branches were stored outside overnight, and then the upper and lower surfaces of needles on five branches were sprayed to drip with commercial aerosol cans of the fire retardant, and five branches (controls) were sprayed with tap water. Branches were allowed to dry outside for $45 \mathrm{~min}$, and then pairs of treated and nontreated branches were suspended on wires spaced $\approx 1 \mathrm{~m}$ apart in a randomized complete block design in a postharvest display room at WSU. Throughout the experiment, ambient temperature and relative humidity were $\approx 20{ }^{\circ} \mathrm{C}\left(68^{\circ} \mathrm{F}\right)$ and $40 \%$ to $50 \%$ respectively. The room was continuously lit with cool-white fluorescent lights, similar to an office or home.

Fraser fir (Abies fraseri). On 7 Mar. 2005, branches were cut from the lower half of eight 2.1- to 2.7-m-tall Christmas trees in a plantation at Laurel Springs, NC. Branches were bundled into tarps by individual tree and transported to Raleigh in an open pickup truck. Ambient temperature was near $0{ }^{\circ} \mathrm{C}$ during collection and transport. Branches from each of the eight trees were divided into bundles of about equal size, with six to seven branches per bundle. Bundles were randomly assigned to one of four treatments: 1) control, displayed dry; 2) control, displayed in water; 3) flame retardant, displayed dry; and 4) flame retardant, displayed in tap water. The experimental RapidCool FRX Christmas Tree Retardant (Goodwin Group, Lynchburg, VA) was mixed in water $(1: 8, \mathrm{v} /$ v) and sprayed onto the upper side of the branches for treatments 3 and 4. After the foliage dried, branches were placed in 19-L buckets, with or without water. A fresh cut was made on the base of each branch placed in tap water. Branches were displayed 4 weeks in a large room maintained at $\approx 20$ ${ }^{\circ} \mathrm{C}$. The room had cool-white fluorescent lighting, as in a home or office, and the relative humidity was $25 \%$ to $45 \%$, with an occasional spike above $60 \%$. This experiment was a randomized complete block with four treatments and eight blocks. Each block (branches from a single tree) consisted of four buckets (one per treatment) arranged in a row, and rows were $0.7 \mathrm{~m}$ apart.

Moisture measurements and flammability tests. Initial and subsequent changes in the MC of Douglas fir and Fraser fir branches were determined periodically during the display period. In the Douglas fir experiment, small twigs were collected from all the branches on each sampling date. In the Fraser fir experiment, small twigs were collected from each branch in not less than four of the eight blocks on each sampling date. In both experiments, after recording fresh weight, twigs were dried to a constant weight at $65{ }^{\circ} \mathrm{C}$, and the resulting dry weight was used to calculate the MC.

In both experiments, branch flammability was tested by holding a $15-\mathrm{cm}$ twig from each branch in a vertical position for $5 \mathrm{~s}$ in a shielded, 2.5-cm flame from an alcohol lamp. For any particular date, either four or eight Fraser fir shoots (replications) and five Douglas fir shoots were sampled for each treatment 
that was included in the flammability test. After removal from the flame, the length of time the flame persisted (flame time), and the total time until the last ember died (burn time) were recorded. In addition, the spread of the flame up the twig and the proportion of the foliage consumed by the fire were rated subjectively. If the sample failed to ignite or if the flame did not spread upon removal of the sample from the flame, it was considered to have passed the flammability test. This protocol is similar to the one used by the California State Fire Marshal (CSFM) to assess flammability of Christmas trees (State of California, 2007). Flammability tests began on day 6 for the Fraser fir and continued through day 29; for Douglas fir, tests spanned days 4 through 17.

Data were analyzed using GLM procedures in SAS 9.1 for Windows (SAS Institute, Cary, NC). Means were plotted graphically (Figs. 1, 2, 3, and 4). Contrasts (1 df) were used to compare pairs of means - with and without retardant-for branches displayed without water.

\section{Results}

Application of the SafeTree Fire Retardant to Douglas fir increased the rate of drying, which increased flammability of the shoots (Fig. 1). By day 6, the MC of the branches that had been treated with the fire retardant was significantly lower than the controls. Although no formal evaluation was carried out, treated branches were also slightly off color. By day 6, the MC of the treated branches averaged $39 \%$ versus $76 \%$ for controls, and all of the treated branches failed the flammability test. Control branches passed the flammability test through day 10 . Although the tips of some of the shoots from these branches charred, the flame failed to spread when the shoots were removed from the flame. There was a transition between day 10 and day 17, after which all of the control branches failed the test. During this time, the proportion of the shoot consumed by the flame also increased.

Applications of RapidCool FRX Christmas Tree Retardant had no effect on the rate of drying of Fraser fir branches displayed dry or in water (Table 1, Fig. 2).

Initial MC was about $115 \%$. When displayed dry, branches dried to $\approx 20 \% \mathrm{MC}$. In water, branch MC increased gradually to $134 \%$ to $142 \%$ during the $29-\mathrm{d}$ display period, indicating that branches contained up to $20 \%$ more water than when cut initially. Moisture content, burn time, flame time, and percentage twig consumption were similar until day 25 (Table 1, Figs. 2, 3, and 4), when flame time became significantly greater for branches treated with retardant (Fig. 3). Percentage twig consumption differed only on day 29, when values for the retardant exceeded those for nontreated branches (Table 1, Fig. 4).

Branches did not ignite and continue to burn when the MC was more than $60 \%$ (Fig. 4). In general, as branches dried to a

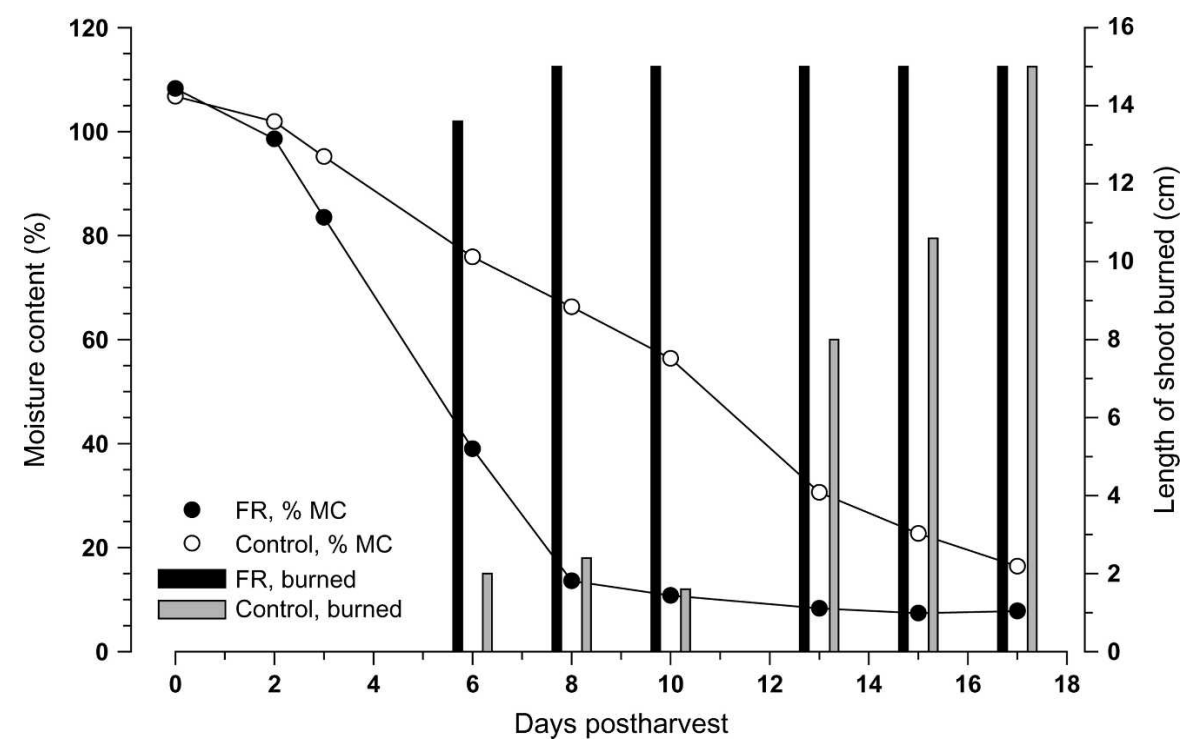

Fig. 1. Effect of treating Douglas fir branches with SafeTree fire retardant (FR) on the rate of moisture loss and flammability of displayed shoots. The axis on the left shows the change in moisture content (MC) with time (line graph). Differences between treated and control MC were significantly different on day $6^{*}, 8^{* *}, 10^{* *}, 13^{*}$, and $15^{*}$. The axis on the right shows the percentage of twigs consumed by fire (bar graph) as $\mathrm{MC}$ decreased. Differences between treated and control shoots were significantly different on day $6^{* *}, 8^{* *}, 10^{* *}$, and $13^{*} . * P \leq 0.05, * * P \leq 0.01 . \mathrm{n}=5$.

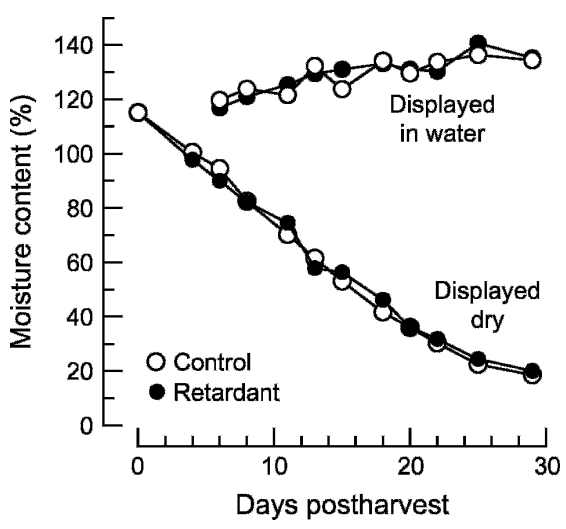

Fig. 2. Effect of RapidCool FRX Christmas Tree Retardant on the moisture content of Fraser fir branches displayed in water or dry. Through day $20, n=4 ; n=8$ thereafter.

lower MC, they 1) ignited quicker, 2) burned more vigorously, and 3) had higher proportions of the foliage consumed, with or without retardant (Figs. 3 and 4). RapidCool flame retardant increased needle loss in one of eight replications (data not presented).

\section{Discussion}

A number of commercial fire retardant products are marketed to reduce the potential fire hazard associated with dry Christmas trees. Fire retardants vary greatly in their composition and performance. In California, when trees are required to be treated with a fire retardant, the product must bear a seal indicating that it has been tested and approved for use on Christmas trees by the CSFM. Outside California, regulations often state that only fire retardants bearing the seal of the CSFM or having a label indicating it

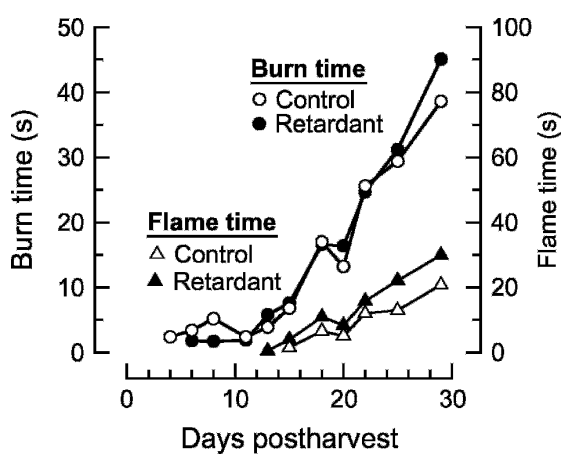

Fig. 3. Effect of RapidCool FRX Christmas Tree Retardant on the burning characteristics of Fraser fir twigs in a burn test when branches were displayed without water. The axis on the left shows the burn time (elapsed time in seconds until the last ember died); the axis on the right shows the flame time (elapsed time in seconds when a flame was visible). Through day $20, n=4 ; n=8$ thereafter.

has been tested by Underwriters Laboratories (or UL) should be used on Christmas trees. New products occasionally appear that, although not bearing the seal of the CSFM, can be tested using protocols similar to those used by the CSFM. Although neither product we tested has the CSFM seal, the SafeTree retardant bears a United States Environmental Protection Agency seal, indicating it is a certified replacement for Halon, a liquefied, compressed gas that halts the spread of fire by chemically disrupting combustion, which is only used in fire extinguishers in a limited number of situations, such as on aircraft. The SafeTree label also includes a statement that reads, "UL listing \#7P21, Class A and B, UL $711 / 162$." The \#7P21 is a UL-proprietary "control number." Class A and B refers to classes of fires, and the 711/162 refers to the 


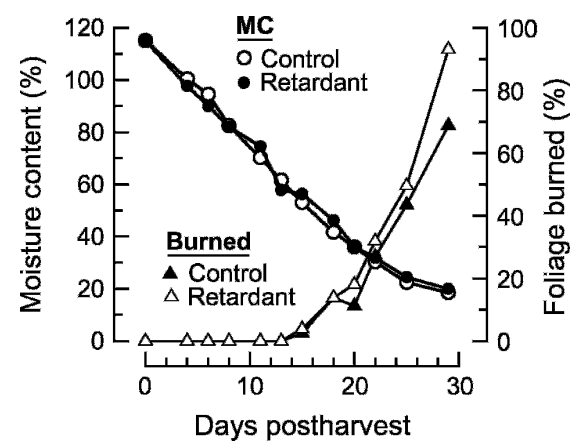

Fig. 4. Effect of RapidCool FRX Christmas Tree Retardant on the moisture content (MC) and percentage of Fraser fir twigs consumed in a burn test when branches were displayed without water. The axis on the left shows the change in MC with time; the axis on the right shows the percentage of foliage consumed as branches became progressively drier. Through day 20 , $\mathrm{n}=4 ; \mathrm{n}=8$ thereafter.

specific UL standards the product meets (http://ulstandardsinfonet.ul.com/scopes/).

There is also a U.S. Department of Agriculture (USDA) Forest Service logo saying, "QPL Approved Specification 5100-307," which means that the product meets the USDA Forest Service specifications for fire suppressant foams to fight wildfires. Although none of these seals and labels relates to the use of this product on Christmas trees, it is unlikely consumers would be aware of this.

Because there is no national testing standard for evaluating the effectiveness and safety of fire retardants on Christmas trees, it is likely that some commercially available products are not effective and might damage Christmas trees or reduce postharvest quality, as noted in earlier studies (Ahrens and Stephens, 1975; Van Wagner, 1963). In our experiments, SafeTree Christmas Tree Fire Retardant increased the rate of drying of Douglas fir branches, which increased flammability. Although applications of RapidCool FRX Christmas Tree Fire Retardant did not adversely affect moisture retention, it did not reduce the flammability of dry Fraser fir branches in this experiment. It is unclear what affect applications of these fire retardants would have on the drying and flammability of other types of conifers.

In the experiment with Fraser fir, the retardant solution was sprayed to runoff on the upper (adaxial) surface of the foliage, which could possibly influence the effectiveness of this product. Most stomata are on the lower (abaxial) side of needles, where the retardant was not applied. It is not known whether applying the material to both surfaces would have affected results. Improved coverage

Table 1. Analysis of burning characteristics of Fraser fir branches with or without flame retardant. ${ }^{\mathrm{z}}$

\begin{tabular}{|c|c|c|c|c|c|}
\hline \multirow[b]{2}{*}{ Source of variation } & \multirow[b]{2}{*}{ df } & \multicolumn{4}{|c|}{ Variable } \\
\hline & & Moisture content & Flame time & Burn time & Amount consumed \\
\hline Rep & 7 & NS & NS & NS & NS \\
\hline Tmt. & 1 & NS & $*$ & NS & NS \\
\hline Date & 9 & $* *$ & $* *$ & $* *$ & $* *$ \\
\hline Tmt. $\times$ date & 9 & NS & NS & NS & NS \\
\hline Contrasts $^{\mathrm{y}}$ & & NS & NS & NS & NS \\
\hline Day 11 & 1 & NS & NS & NS & NS \\
\hline Day 15 & 1 & NS & NS & NS & NS \\
\hline Day 20 & 1 & NS & NS & NS & NS \\
\hline Day 22 & 1 & NS & NS & NS & NS \\
\hline Day 25 & 1 & NS & $*$ & NS & NS \\
\hline Day 29 & 1 & NS & $*$ & NS & $*$ \\
\hline$R^{2}$ & & 0.94 & 0.63 & 0.74 & 0.75 \\
\hline
\end{tabular}

${ }^{\mathrm{z}}$ Comparison of branches that were displayed dry, with and without flame retardant.

${ }^{\mathrm{y}}$ Through day $20, \mathrm{n}=4 ; \mathrm{n}=8$ for longer durations.

ns,,${ }^{* * *}$ Nonsignificant or significant at $P=0.05$ or 0.01 respectively.

Tmt., treatment; Rep, branch from a single tree.

is unlikely to reduce the drying rate, because studies with antitranspirants have shown these products have little effect on the drying rate of Douglas fir Christmas trees even when applied by submerging the trees in a vat, followed by drying (Montano and Proebsting, 1986). Virtually all flame retardants are applied by sprayers. High-pressure sprayers, as used by growers, can thoroughly wet the foliage, whereas hand-held aerosol cans or hand-held or backpack sprayers that would typically be used by retail lot operators or consumers are likely to do little more than wet the foliage on the perimeter of the crown.

In our studies, flammability was closely related to $\mathrm{MC}$, with or without flame retardant (Figs. 1 and 4). Flames self-extinguished when $\mathrm{MC}$ was $\geq 60 \%$. When displayed in water, the MC of the Fraser fir branches actually increased to levels well above initial values, indicating $\approx 20 \%$ more water content than at the outset. Similar observations have been reported in other experiments (Chastagner and Riley, 2003; Davis and Fretz, 1972; Hinesley and Snelling, 1994; Van Wagner, 1963). Because fresh trees did not readily ignite and burn, the extra water gained during display would further reduce any chance of ignition from a small ignition source. These results again confirm that displaying a cut Christmas tree in water is the most reliable way to maintain its freshness and to reduce potential fire hazards.

\section{Literature Cited}

Ahrens, J. and G.R. Stephens. 1975. The effects of additives on freshness and flammability of Christmas trees. Bul. 760. Conn. Agr. Expt. Sta., New Haven, CT.

Babrauskas, V., G.A. Chastagner, and E. Stauss. 2001. Flammability of Christmas trees. Proc.
Intl. Assn. of Arson Investigators Conf., 21-24 May 2001, Atlantic City, NJ.

Chastagner, G.A. 1990. Keeping cut trees fresh. Northwest Christmas Tree Assn. Christmas Tree Lookout 23:32-34, 37-40, 42-44.

Chastagner, G.A. and K.L. Riley. 2003. Postharvest quality of noble and Nordmann fir Christmas trees. HortScience 38:419-421.

City of Anaheim. n.d. Christmas trees in public buildings: Specifications and requirements. Fire Dept., Fire Prevention Bur., Anaheim, CA.

Davis, T.S. and T.A. Fretz. 1972. The anti-transpirant effect on harvested Christmas trees. Amer. Christmas Tree J. 16:3-5.

Gwinnett County Fire Marshal. 2006. Christmas trees and holiday decorations. Administrative rule no. 06-0006. Dept. of Fire and Emergency Services, Lawrenceville, GA.

Hinesley, L.E. and L.K. Snelling. 1994. Postharvest drying of Leyland cypress, eastern red cedar, and Fraser fir Christmas trees. HortScience 30:1427-1428.

Koelling, M.R. 1998. Christmas trees do not cause fires: Some facts! Amer. Christmas Tree J. $42: 4,6,8,10,12,14,16,18-21$.

Montano, J.M. and W.M. Proebsting. 1986. Storage of cut Douglas fir: Relationship to the damage threshold. HortScience 21:1174 1175 .

National Fire Protection Association. 2006a. Fire statistics: Leading causes of structure fires in homes, 1999-2002 averages. Natl. Fire Protection Assoc., Quincy, MA.

National Fire Protection Association. 2006b. Fire statistics: Leading causes of structure fires in homes, 1999-2002: Annual averages reported to U.S. Fire Departments. Natl. Fire Protection Assoc., Quincy, MA.

Ohio Dept. of Commerce. 2004. Holiday fire code. State Fire Marshal News, Fall 2004. Reynoldsburg, Ohio.

State of California. 2007. California administrative code title 19 , section 1264.3

Van Wagner, C.E. 1963. Flammability of Christmas trees. Publ. no. 1034. Canada Dept. For., Forest Res. Branch, Ottawa, Canada. 